\title{
The Storytelling Brain: How Neuroscience Stories Help Bridge the Gap between Research and Society
}

\author{
DiD Susana Martinez-Conde, ${ }^{1}$ Robert G. Alexander, ${ }^{1}$ Deborah Blum, ${ }^{2}$ Noah Britton, ${ }^{3}$ Barbara K. Lipska, ${ }^{4}$ \\ [CGregory J. Quirk, ${ }^{5}$ Jamy Ian Swiss, ${ }^{6}{ }^{\circ}$ Roel M. Willems, ${ }^{7,8}$ and ${ }^{\circledR}$ Stephen L. Macknik ${ }^{1}$ \\ ${ }^{1}$ State University of New York Downstate Health Sciences University, Brooklyn, New York 11203, ${ }^{2}$ Knight Science Journalism Program, Massachusetts \\ Institute of Technology, Cambridge, Massachusetts 02139, ${ }^{3}$ Bunker Hill Community College, Boston, Massachusetts 02129, ${ }^{4}$ National Institute of Mental \\ Health, National Institutes of Health, Bethesda, Maryland 20892, ${ }^{5}$ University of Puerto Rico School of Medicine, 00936 San Juan, Puerto Rico, ${ }^{6}$ San Diego, \\ California 92116, ${ }^{7}$ Centre for Language Studies and Donders Institute for Brain, Cognition and Behaviour, Radboud University, 6500 Nijmegen, The \\ Netherlands, and ${ }^{8}$ Max Planck Institute for Psycholinguistics, 6525 XD Nijmegen, The Netherlands
}

Active communication between researchers and society is necessary for the scientific community's involvement in developing sciencebased policies. This need is recognized by governmental and funding agencies that compel scientists to increase their public engagement and disseminate research findings in an accessible fashion. Storytelling techniques can help convey science by engaging people's imagination and emotions. Yet, many researchers are uncertain about how to approach scientific storytelling, or feel they lack the tools to undertake it. Here we explore some of the techniques intrinsic to crafting scientific narratives, as well as the reasons why scientific storytelling may be an optimal way of communicating research to nonspecialists. We also point out current communication gaps between science and society, particularly in the context of neurodiverse audiences and those that include neurological and psychiatric patients. Present shortcomings may turn into areas of synergy with the potential to link neuroscience education, research, and advocacy.

Key words: science communication; storytelling; science outreach; broader impact; science reporting; scientific journalism

\section{Introduction}

Researchers worldwide have started to realize that communication with society is necessary for our involvement in developing science-based policies. This newfound awareness culminated in the 2017 March for Science, with an estimated global attendance of more than one million people. Increasingly, institutional and funding agency policies around the world, including the Royal Society in the United Kingdom, the Centre National de la Recherche Scientifique in France, the Max Planck Society in Germany, and the National Science Foundation in the United States, compel scientists to engage more with the public, and to disseminate research findings in an accessible fashion. Along similar lines, there have been calls for scientists and journalists to join forces in their common endeavor of unveiling objective facts and dispelling misinformation. Yet, too often, researchers remain unsure of how to approach science communication, feel they lack the tools to undertake it, or receive mixed signals about the pros and cons of public outreach (Martinez-Conde, 2016; Martinez-Conde et al., 2016).

Part of the problem is insufficient or inadequate training in the necessary skillset. As a result, many scientists assume a stan-

Received June 24, 2019; revised Aug. 12, 2019; accepted Aug. 16, 2019.

This work was supported by the National Science Foundatoin Award 1439189 to S.M.-C. and Award 1734887 to S.M.-C. and S.L.M., and The Netherlands Organization for Scientific Research Vidi Grant 276-89-007 to R.W.

The authors declare no competing financial interests.

Correspondence should be addressed to Susana Martinez-Conde at smart@neuralcorrelate.com.

https://doi.org/10.1523/JNEUROSCI.1180-19.2019

Copyright $\odot 2019$ the authors dard lecturer approach when attempting to engage broad audiences, believing that, if the public is simply given more accessible information, societal support for scientific and technological issues will increase accordingly. However, the evidence indicates that many barriers stand in the way of effective communication, and that simply providing more information does not necessarily change popular but incorrect views, as difficulties extend beyond the complexity of the material (National Academies of Sciences, Engineering and Medicine, 2017; Attanasio, 2018). Narrative science storytelling may improve these efforts, helping to engage listeners and lead policy change (Oliver and Cairney, 2019).

For purposes of discussion, it may be useful to define what "narrative science storytelling" means in this context. According to Webster's dictionary, a narrative is a "discourse designed to connect a series of happenings" (Webster, 1969). In narrative storytelling, the narrator (or author) deliberately uses techniques, including voice, character, suspense, and description, to both connect the disparate elements involved and to create a compelling and readable story (Chaitin, 2003). For professional science writers, these narrative choices are aimed at making science information inclusive, seeking to help build a larger and more science literate audience (Blum, 2014). But those same techniques may also be useful to scientists seeking to engage a variety of audiences with their work.

The magician Michael Weber has affirmed that "whoever tells the best story wins" (personal communication to J.I.S; sometimes attributed to John Quincy Adams). Though Webber referred to the performance of magic, asserting that magic that best incor- 
porates "story" in an effective, engaging, meaningful fashion will produce the most impactful result, it reflects an even broader truth: that the best stories win in politics, in history, in criminal justice, and even in arenas guided by a focus on objectively testable claims, namely, science.

Storytelling engages not just people's intellect, but also their feelings: a bald recitation of facts invariably lacks the impact (and the enduring power) of a coherent narrative that awakens one's emotions. Indeed, when major discoveries generate little interest among the lay public, there is likely a disconnect between the scientific content and its emotional impact. Similarly, when large sections of society are used to relying on misinformation and biased data, pointing to scientific facts is not effective. Recent research indicates that the truth or falsehood of a story does not necessarily influence people's reactions to it, or their appreciation of the narrative (Hartung et al., 2017). Further, people choose information sources with which they share personal biases and beliefs (Higgins, 2016). Emotional engagement generated through personal science narratives could help counteract these predispositions and generate the audience involvement that traditional science communication has found lacking. Narrative improves information processing, increasing recall of, and interest in, the story (Glaser et al., 2009; Hong and Lin-Siegler, 2012). Moreover, narrative increases recall of any scientific material presented in the story (Töpper et al., 2014).

Because storytellers have significant freedom to craft narratives, they can effectively convey information about multivariate components of the scientific endeavor, from the experimental results themselves to the human efforts behind the studies. Stories about how scientists struggled either intellectually or in their personal lives, and then overcame those struggles, have been shown to improve not only the engagement of high school students in science materials, but also boost academic performance (Lin-Siegler et al., 2016). First-person narratives, in particular, can make science personally relevant and encourage personal investment in the topic (Downs, 2014).

Where research communication by and for academics typically downplays emotion, narrative storytelling can be used to capture lay audiences and encourage excitement about important scientific discoveries that may not have clear or immediate applied value (Martinez-Conde and Macknik, 2017b). In a recent study, embedding climate change information in an emotional story structure affected proenvironmental donation behavior. Thus, eliciting emotional arousal likely improves the odds that listeners will not only engage with the material, but also act on it as a result (Morris et al., 2019). Most researchers have at some point experienced astonishment and wonder in connection with research findings: there is every reason to believe that those same discoveries can prompt similar emotions in nonspecialists. Evoking emotions and wonder is sometimes achieved by not telling a straightforward story. Research shows that a story with fictional characters that act in a morally or emotionally ambiguous fashion leads to a deeper (moral) evaluation in the reader or viewer (e.g., Eden et al., 2017). Thus, if one wants to evoke (moral) reflection via a science narrative, it may be better to not make the moral content of the narrative too straightforward, but rather more ambiguous. This allows for more "moral rumination" (a term coined by American psychologist John Dewey) in the reader than a simple "from A to B" narrative.

Here we explore some of the techniques intrinsic to crafting scientific narrative, as well as the reasons why scientific storytelling may be an optimal way of communicating research discoveries to broad audiences. Importantly, whereas some scientists believe that science communication means extreme simplification, we argue instead for a narrative approach that does justice to the science while also inspiring the general public. The sections below are centered on the lectures and personal stories presented during the 2019 Storytelling Session at the Society for Neuroscience annual conference.

\section{Our storytelling brains}

The neuroscience of language has traditionally focused on understanding how the comprehension and production of words and single sentences is implemented in our brains. Despite the importance of stories in our everyday lives, the neuroscience of narrative has only recently begun to be an area of active research. An interesting observation from this line of work is that regions that are not traditionally thought to be part of a "language network" in the brain become consistently activated when people listen to narratives. Example areas are the precuneus/posterior cingulate cortex, and mPFC. Indeed, in a relatively early observation, Ferstl et al. (2008) made the case for an "extended language network," including these areas next to traditional temporal and inferior frontal "language" regions. The posterior midline activations have been linked to the larger time span of narratives (compared with single sentences) (Lerner et al., 2011). The medial prefrontal activations, in turn, have been related to the "mentalizing" aspects (Tamir et al., 2016) and immersive properties (Hsu et al., 2014) of narratives.

An intriguing point to note is the overlap of the regions activated during narrative comprehension and the so-called default mode network (Buckner and Carroll, 2007; Buckner et al., 2008; Hassabis et al., 2014; Yuan et al., 2018). This overlap may be meaningful in the sense that the "resting state" invites narrative construction. The type or content of the mind wandering that takes place during the resting state is unconstrained (and unknown), but it is conceivable that it has narrative structure (Jacobs and Willems, 2018). In extension to the view that the default mode network is the brain's "default" working mode, the research on narrative comprehension suggests that this default could be more closely related to narratives than appreciated so far, a position that should interest neuroscientists interested in resting state studies.

Is there another reason for researchers to be interested in narratives and their neural underpinnings? The interest for neuroscientists across disciplines is that narratives naturally contain parts of cognition that are traditionally studied in artificial task contexts, making narratives an ideal research tool to study cognition in a more contextualized fashion (Willems and Jacobs, 2016). Indeed, recent work has started to use narratives to gain better understanding of classical research topics in neuroscience. Examples are language comprehension (Chow et al., 2014; Lopopolo et al., 2017), social understanding (Tamir et al., 2016), memory encoding (Milivojevic et al., 2016), and event segmentation (Whitney et al., 2009; Zacks et al., 2010; for extensive discussion, see Hasson et al., 2018). In the next section, we discuss mental simulation as an example of a research topic that lends itself well for study using narratives.

\section{The stories playing in our mind's theater}

A research topic that lends itself perfectly for study within a narrative context is mental simulation. Part of the pleasure that we derive from engaging with narratives lies in their potential to evoke mental images. We do not just process the words and sentence on a page, but we can experience what happens in the story in a vivid manner, by mentally simulating the content of a narra- 
tive. We can see what is being described, and even feel what the characters feel, using our own minds to live the fiction world.

The laboratory of R.M.W. has empirically studied mental simulation during narrative understanding (Willems and Jacobs, 2016). Their work distinguishes between more "literal" and more "social" mental simulations. The first are related to the concrete actions or sensory descriptions that are part of a story (i.e., the description of scenery or a main character that rushes through traffic on her way home). The second refer to descriptions of mental states, such as the thoughts, intentions, and feelings of characters. Both types of simulations are important for building up a mental story world.

R.M.W. and collaborators have measured brain activation and eye movements during reading, followed by postreading selfreports (on readers' engagement with, and appreciation of, the narratives). Their data provide an indication of how "sensitive" a given reader may be to the different parts of the narrative that allow for mental simulation. Recent results have revealed a critical effect of personal preference in the reader's experience (sometimes even more so than the specifics of the story). For instance, whereas changing the narrative perspective (from "she" to "I") does not appear to influence the mental simulations of readers (Hartung et al., 2017), some readers do prefer sensorimotor simulations, and others prefer mental state simulations (Nijhof and Willems, 2015).

Surprisingly, the researchers also found that action descriptions speed up reading, whereas mental state descriptions slow down reading (Mak and Willems, 2019). The discovery that action descriptions speed up reading is counterintuitive, as imagining actions is known to be time-consuming and suggests that the mental images formed during reading are unlike those that we deliberately form, for instance, when we relive an experience.

Future research will need to uncover the specifics of mental simulation during narrative. What is important to note here is that, by using narratives, the researchers were able to tap into mental simulation as it unfolded naturally in readers. This revealed individual differences that tend to go overlooked in more constrained task settings.

\section{Tell the truth, but tell it slant}

In the current era of post-truth gloom, the quest for objective truth has become more critical than ever. There have been calls for scientists and journalists to join forces in this common endeavor and call out falsehoods, whether due to innocent mistakes or frank attempts to mislead (Martinez-Conde and Macknik, 2017a). Indeed, science journalism programs, such as the Knight Science Journalism Program at the Massachusetts Institute of Technology, have already begun programs focused on integrity of story and detailed fact-checking of information (Borel et al., 2018). This echoes the basic premise of the scientific method, which teaches us that we only attain truth by stubbornly stripping away the misinformation that stands in its way (Martinez-Conde and Macknik, 2017a). Accuracy is essential in even the best narrative, which draws its power from the truths that underlie the story.

D.B., a newspaper science journalist and Pulitzer prize winner, explains that her storytelling is firmly grounded in scientific facts:

“Tell all the truth but tell it slant, success in circuit lies,' once wrote the great 19th century American poet Emily Dickinson (Dickinson, 2000). And she concluded that verse with, 'The truth must dazzle gradually, lest every man be blind.' I realized early on that I needed to find ways to seduce readers, who might not be very interested in science, into my subject. Dickinson's words inspired me to let the story itself carry readers through the more challenging technical issues in the science."

"My journey into narrative science storytelling started with the Dickinson quote because of its emphasis on truth; accuracy is an essential part of science writing. But I also felt that what brings readers to science are not the facts themselves, but how the narrator crafts the tale. Rather than preaching to the choir by writing for a readership that already supports science, I strive to bring back to the fold those who have turned away and concluded that science is boring, hard, and not important to their lives, when indeed it is the opposite: fascinating and essential to our daily existence."

"I have turned over and over to storytelling techniques to allow scientific truths to dazzle. My book Love at Goon Park, for instance, follows the life of the controversial, eccentric, and brilliant 20th century psychologist, Harry Harlow, to explore the science of relationships, and pursue the essential question of why family and friendship are so important to human health. More recently, my book, The poisoner's handbook, tells the story of two crusading scientists in the 1920s as they tried to figure out how to catch killers, letting the true stories of a murderous decade in New York City provide the backdrop for explaining the basic chemistry of poisons. This book is in current use in multiple high school classes as a way to show students that chemistry is fascinating."

\section{The magic in storytelling}

Storytelling is important in human cognition and human interaction, and perhaps especially so in performance and narrative arts, from literature to standup comedy, to theater, cinema, and stage magic.

Here we focus on the performance of magic, which like science communication, inherently encompasses a story. Further parallels may be drawn between the changes that take place during a magic show and those that occur in the course of a scientific discovery. Thus, investigating the structure of magic performances could help us identify what makes for a good science story.

J.I.S., a professional magician, writer, and activist in the world of scientific skepticism (the social movement that promotes a scientific worldview, critical thinking, and rational inquiry), is interested in the role of storytelling in magic and how it may relate to that in other performance arts:

"Storytelling in magic performances (and likely in other narrative forms too) can be explicit or implicit. The explicit use of narrative in magic includes performances that are accompanied by a spoken word 'story.' This kind of 'presentation' (a term used by magicians to describe such scripting) has long been an element of conjuring. More recently, the explicit use of story has been heralded within certain artistic circles in magic, as exemplified by Jeff McBride's 'Mystery School' in Las Vegas, one of the only existing schools organized for the study of magic."

"Whereas the explicit use of storytelling in magic has its limits, 'story' itself may be implicit to magic. When Teller, of Penn and Teller, says that 'Every magic trick is a story' (personal communication), what he is likely alluding to is that every magic trick possesses an inherent plot, with a 
beginning, a middle, and an end. This is so because every magical 'effect' involves a change of state, to wit: An object is present. It vanishes. The object is gone. Or: An object is green. It transforms. It is now red. Or: An object is destroyed. A magical transformation occurs. The object is restored. Hence, every magic trick is a story, even in the absence of a spoken script."

The above-mentioned convergence between magic and scientific storytelling also suggests that breaking down magic stories and investigating them scientifically could help researchers understand the psychological and neuroscientific mechanisms of storytelling. From this perspective, magic could provide a protocol of investigation of cognitive mechanisms, which might elucidate how the brain tracks and perceives change, a major constituent of storytelling.

Whereas a shared interest in the human experience has already resulted in fruitful collaborations between magicians and neuroscientists (Macknik et al., 2008; Cui et al., 2011; OteroMillan et al., 2011; Rieiro et al., 2013), scientists have just begun to investigate the impact of narrative on the magic experience (Williams and McOwan, 2014). J.I.S. proposes that future research on magic may attempt to isolate and examine features that set magic apart from other performing arts, and the audience's experience of those arts.

At the heart of strong magic lies an experience of cognitive dissonance that is not a requisite element of other performance or narrative arts. Magic at its best confronts the viewer with an inherently dissonant experience, namely, convincing visual evidence of an event or phenomenon that the viewer knows intellectually to be impossible. Whereas magicians routinely put to use the cognitive toolkit that all theatrical artists have used for millennia, they also create an experience unlike those produced by other arts.

Yet, the cognitive dissonance that is inherent to magic tricks can lead to frustration and resentment, which can manifest in audiences as heckling, proposing supposed (and often wrong) explanations of the tricks, and other challenges. Magicians' use of explicit storytelling is often in service to resolving dissonance: not by providing an explanation, but by engaging spectators' emotions, including the experience of wonder. The magician Whit Haydn speaks of this dissonance as a "pointy place" that people find it uncomfortable to sit on. Thus, he says: "The sword of magic is concealed in the cloak of theater."

Further areas of collaboration between magicians and scientists, exemplified by historical and contemporary conjurers, such as Harry Houdini, James Randi, and J.I.S. himself, are in the efforts to debunk pseudoscientific thinking and practices (including psychic fraud and other new age theosophies). This work, which currently extends to dispelling misinformation in areas such as climate change, or the antivaccination movement, may also benefit from the lessons of narrative storytelling.

Thus far, we have addressed storytelling, as well as its neural bases and consequences, in the context of neurotypical brains. Next, we consider the unique challenges and opportunities that neuroscience communication and storytelling present in the context of neurodivergent speakers and/or neurodiverse audiences.

\section{Who gets to tell the story? Science communication, neurodiversity, and personal advocacy}

Storytelling is intimately linked with the culture and background of the storyteller. Historically, the white/male perspective has dominated science stories, but this is changing as STEM graduate students are increasingly female and cross-cultural. Individuals from different cultures may be primed to hear science stories from their own cultural perspective, finding more relevance. G.J.Q. describes his scientific mentoring in Puerto Rico:

"Creating a family-like atmosphere in the laboratory facilitates group cohesiveness and increases communication skills in Latino trainees (Quirk, 2019). The effort by scientific societies to make symposium panels more gender and ethnically diverse is changing the face of the scientific communicator and generating role models that will help science stories evolve."

Although the intersection of neurodiversity and science communication is a more recent concept, it has achieved significant appreciation and media presence, in no small part thanks to the 16-year-old environmental activist Greta Thunberg. Thunberg, who is autistic, has made the argument that her neurodivergence has helped her see through propaganda and political misdirection concerning climate change. She asserts that she became an activist not despite her autism, but because of it (Silberman, 2019).

Neuroscience storytelling presents the possibility, as well as the challenge, of discussing brain function, and individual differences in neural processing, while engaging the brains of 'differently wired' individuals. Future efforts should aim to deepen current understanding of the science and society interface in the context of neurodiverse audiences, or those integrated by patients and their communities. Such an exchange may be especially powerful when the science communicators are themselves neurodivergent or afflicted with neurological and/or psychiatric disorders. In those cases, communicators may be particularly well suited to bridge existing gaps between neuroscience education, research, and advocacy. The following subsections are concerned with science communication by speakers and/or for audiences on the autism spectrum (Science communication on the spectrum), or suffering from mental illness (Destigmatizing and improving communication on mental illness).

\section{Science communication on the spectrum}

In 2006, 4 years after having been diagnosed with Asperger's, N.B. attended a lecture on autism at an academic institution. His experience illustrates a communication gap between autism researchers and people who are autistic:

\footnotetext{
"Since my diagnosis, I had spent significant time studying primary sources, the writings of other people in the autism spectrum, and come to understand that some personal features that I thought unique, such as being hyperflexible (Curdlesnoot, 2007), or disliking being called by my given name (Analkant, 2009), were autistic traits. I felt that selfreported stories had the potential to help researchers who might be otherwise unaware of the observations and experiences of autistic authors."

“Thus, when the speaker speculated that autistics' gazes are drawn more to mouths than eyes because mouths are the source of speech (Klin et al., 2002), I objected that such behavior arises not from the mouth's movement as an attractive force, but from direct eye contact gaze as an aversive force for people on the spectrum. Because my argument was based on personal experience, it was dismissed as subjective."
} 
Although more recent research now acknowledges that eye contact is aversive to autistics (Neumann et al., 2006), collaborative efforts between autism researchers (who are frequently neurotypical) and autistic individuals (who are life-long experts) are too often lacking, leading to missed opportunities and delaying research advances.

Autistics' descriptions of their own experiences, and their observations of the ways in which they differ from neurotypicals, are invaluable sources of hypotheses to investigate, as well as ways of properly interpreting research. Some such stories are available at \#actuallyautistic.

\section{Destigmatizing and improving communication on mental illness}

Mental disorders cost the United States significantly more than any other medical condition: close to $\$ 200$ billion in lost earnings alone (National Institutes of Health, 2008). Finding cures for mental illness is an important issue at a societal level, and also because patients and their families suffer greatly. Yet, despite decades of modern research on mental illness, including relatively recent studies of the structure of human genome and genetic associations by thousands of dedicated scientists (Wellcome Trust Case Control Consortium, 2007; Gormley et al., 2016), present understanding of the causes and underlying mechanisms of mental illness remains unsatisfactory. As a consequence, successful treatment is often elusive. Recent data suggest that mental illness is caused by a combination of heredity and environment, the latter involving multiple factors, including malnutrition, prenatal and birth complications, stress, drug abuse, and others (Howes and Murray, 2014; Nimgaonkar et al., 2017; Misiak et al., 2018), which act in complex interplay with one another and with an individual's genes. But it remains exceedingly hard to identify the biological and chemical processes for mental illness, in part because these disorders are diagnosed through observations of behaviors rather than through more precise tests. Unlike cancer and heart disease, mental illness has no objective measures; there are no biological markers in current use that help diagnose mental illness. It is also becoming clear that specific mental disorders are not well categorized. There is some evidence that various mental illnesses overlap at the level of behaviors as well as their neurobiological substrates (Witt et al., 2017). For example, there is current scientific consensus that the PFC is the main site of disruption in people with schizophrenia (Selemon and Zecevic, 2015), although its network of connections with other parts of the brain may be abnormal, too. Yet, what these abnormalities are and how exactly the brain malfunctions in any given mental problem remain largely unknown.

These difficulties contribute to, and are compounded by, the association of mental illness with societal stigma (Carrara et al., 2019; Charette-Dussault and Corbière, 2019; Heim et al., 2019). Improved communication among researchers, clinicians, patient communities, and the public may mitigate stigma by conveying that mental illness is a brain disease, and not fundamentally different from ailments that affect other organs of the body, such as heart or kidney disease.

B.K.L., a scientist who specializes in the study of mental disorders, was diagnosed in 2015 with metastatic melanoma and underwent immunotherapy treatment. The resulting frontal cortex inflammation presented as mental illness:

"I experienced not just the terror and difficulty of living with mental illness (Lipska and McArdle, 2018), but also how other people react to mentally ill individuals. I had first-hand evidence that mental illness is a disease of the brain (Insel and Cuthbert, 2015). My outlook on mental illness shifted to being more tolerant, understanding, and motivated to share knowledge about brain and mental disorders."

B.K.L.'s unique perspective, as both a patient and a neuroscientist, lends great weight to her message on the importance of addressing mental illness as a brain disease, and what neuroscience as a field can do to reduce the stigma of such ailments in society.

In conclusion, there is a compelling need for researchers to disseminate their findings widely to the public in an accessible fashion. The audiences for these communications may include those who are disinterested in science, as well as people with widely varying preferences for how material is presented. Communicators themselves may differ in their approaches, as well as in their first-person experiences of their area of study. Here we argue that crafting objective, replicable facts into narrative scientific storytelling is an effective means of communicating research discoveries to nonspecialists. Storytelling not only creates emotional connections to draw in the listener, but, like the narratives that often accompany magic performances, can help ease an audience's discomfort or frustration with the information presented. Thus, well-crafted stories can help neuroscientists close communication gaps between science and society, especially in the case of neurodiverse and patient populations.

\section{References}

Analkant (2009) Does anyone else? Asperger Livejournal. https://asperger. livejournal.com/2215125.html.

Attanasio R (2018) Communicating environmental sciences: public discourse and policy development. Integr Environ Assess Manag 14:167168.

Blum D (2014) Introduction. In: The best American science and nature writing (Blum D, Folger T, eds), pp xv-xxiii. Boston: Houghton Mifflin Harcourt.

Borel B, Sheikh K, Husain F, Junger A, Biba E, Blum D (2018) The state of fact-checking in science journalism. Cambridge, MA: Massachusetts Institute of Technology Knight Science Journalism Program.

Buckner RL, Carroll DC (2007) Self-projection and the brain. Trends Cogn Sci 11: 49-57.

Buckner RL, Andrews-Hanna JR, Schacter DL (2008) The brain's default network. Ann N Y Acad Sci 1124: 1-38.

Carrara BS, Ventura CA, Bobbili SJ, Jacobina OM, Khenti A, Mendes IA (2019) Stigma in health professionals towards people with mental illness: an integrative review. Arch Psychiatr Nurs 33:311-318.

Chaitin J (2003) Narratives and story-telling. In: Beyond intractability. Burgess G, Burgess H (eds). Conflict information consortium, University of Colorado, Boulder. Available at http://www.beyondintractability.org/essay/narratives.

Charette-Dussault É, Corbière M (2019) An integrative review of the barriers to job acquisition for people with severe mental illnesses. J Nerv Ment Dis 207:523-537.

Chow HM, Mar RA, Xu Y, Liu S, Wagage S, Braun AR (2014) Embodied comprehension of stories: interactions between language regions and modality-specific neural systems. J Cogn Neurosci 26:279-295.

Cui J, Otero-Millan J, Macknik SL, King M, Martinez-Conde S (2011) Social misdirection fails to enhance a magic illusion. Front Hum Neurosci 5:103.

Curdlesnoot R (2007) Hyper extensive limbs. Asperger Livejournal. https:// asperger.livejournal.com/1425016.html.

Dickinson E (2000) The poems of Emily Dickinson: reading edition (Franklin, RW, ed). Durham, NC: Duke UP.

Downs JS (2014) Prescriptive scientific narratives for communicating usable science. Proc Natl Acad Sci U S A, 111 [Suppl 4]:13627-13633.

Eden A, Daalmans S, Van Ommen M, Weljers A (2017) Melfi's choice: morally conflicted content leads to moral rumination in viewers. J Media Ethics 32:142-153.

Ferstl EC, Neumann J, Bogler C, von Cramon DY (2008) The extended 
language network: a meta-analysis of neuroimaging studies on text comprehension. Hum Brain Mapp 29:581-593.

Glaser M, Garsoffky B, Schwan S (2009) Narrative-based learning: possible benefits and problems. Communications 34:429-447.

Gormley P, Anttila V, Winsvold BS, Palta P, Esko T, Pers TH, Farh KH, Cuenca-Leon E, Muona M, Furlotte NA, Kurth T, Ingason A, McMahon G, Ligthart L, Terwindt GM, Kallela M, Freilinger TM, Ran C, Gordon SG, Stam AH, et al. (2016) Meta-analysis of 375,000 individuals identifies 38 susceptibility loci for migraine. Nat Genet 48:856-866.

Hartung F, Hagoort P, Willems RM (2017) Readers select a comprehension mode independent of pronoun: evidence from fMRI during narrative comprehension. Brain Lang 170:29-38.

Hartung F, Withers P, Hagoort P, Willems RM (2017) When fiction is just as real as fact: no differences in reading behavior between stories believed to be based on true or fictional events. Front Psychol 8:1618.

Hassabis D, Spreng RN, Rusu AA, Robbins CA, Mar RA, Schacter DL (2014) Imagine all the people: How the brain creates and uses personality models to predict behavior. Cereb Cortex 24:1979-1987.

Hasson U, Egidi G, Marelli M, Willems RM (2018) Grounding the neurobiology of language in first principles: the necessity of non-languagecentric explanations for language comprehension. Cognition 180:135-157.

Heim E, Henderson C, Kohrt B, Koschorke M, Milenova M, Thornicroft G (2019) Reducing mental health-related stigma among medical and nursing students in low-and middle-income countries: a systematic review. Epidemiol Psychiatric Sci. Advance online publication. Retrieved Apr 1, 2019. doi: $10.1017 /$ S2045796019000167.

Higgins K (2016) Post-truth: a guide for the perplexed. Nature 540:9.

Hong HY, Lin-Siegler X (2012) How learning about scientists' struggles influences students' interest and learning in physics. J Educ Psychol 104:469.

Howes OD, Murray RM (2014) Schizophrenia: an integrated sociodevelopmental-cognitive model. Lancet 383:1677-1687.

Hsu CT, Conrad M, Jacobs AM (2014) Fiction feelings in Harry Potter: haemodynamic response in the mid-cingulate cortex correlates with immersive reading experience. Neuroreport 25:1356-1361.

Insel TR, Cuthbert BN (2015) Brain disorders? Precisely. Science 348:499-500.

Jacobs AM, Willems RM (2018) The fictive brain: neurocognitive correlates of engagement in literature. Rev Gen Psychol 22:147-160.

Klin A, Jones W, Schultz R, Volkmar F, Cohen D (2002) Visual fixation patterns during viewing of naturalistic social situations as predictors of social competence in individuals with autism. Arch Gen Psychiatry 59:809-816.

Lerner Y, Honey CJ, Silbert LJ, Hasson U (2011) Topographic mapping of a hierarchy of temporal receptive windows using a narrated story. J Neurosci 31:2906-2915.

Lin-Siegler X, Ahn JN, Chen J, Fang FFA, Luna-Lucero M (2016) Even Einstein struggled: effects of learning about great scientists' struggles on high school students' motivation to learn science. J Educ Psychol 108:314.

Lipska BK, McArdle E (2018) The neuroscientist who lost her mind: my tale of madness and recovery. Boston: Houghton Mifflin Harcourt.

Lopopolo A, Frank SL, van den Bosch A, Willems RM (2017) Using stochastic language models (SLM) to map lexical, syntactic, and phonological information processing in the brain. PLoS One 12:e0177794.

Macknik SL, King M, Randi J, Robbins A, Thompson J, Martinez-Conde S (2008) Attention and awareness in stage magic: turning tricks into research. Nat Rev Neurosci 9:871-879.

Mak M, Willems RM (2019) Mental simulation during literary reading: individual differences revealed with eye-tracking. Lang Cogn Neurosci 34:511-535.

Martinez-Conde S (2016) Has contemporary academia outgrown the Carl Sagan effect? J Neurosci 36:2077-2082.

Martinez-Conde S, Macknik SL (2017a) The delusion of alternative facts. Illusion Chasers. https://blogs.scientificamerican.com/illusion-chasers/ the-delusion-of-alternative-facts/.

Martinez-Conde S, Macknik SL (2017b) Opinion: finding the plot in science storytelling in hopes of enhancing science communication. Proc Natl Acad Sci U S A 114:8127-8129.
Martinez-Conde S, Macknik SL, Powell D (2016) The plight of the celebrity scientist. Sci Am 315:64-67.

Milivojevic B, Varadinov M, Vicente Grabovetsky A, Collin SH, Doeller CF (2016) Coding of event nodes and narrative context in the hippocampus. J Neurosci 36:12412-12424.

Misiak B, Stramecki F, Gaweda L, Prochwicz K, Sasiadek MM, Moustafa AA, Frydecka D (2018) Interactions between variation in candidate genes and environmental factors in the etiology of schizophrenia and bipolar disorder: a systematic review. Mol Neurobiol 55:5075-5100.

Morris BS, Chrysochou P, Christensen JD, Orquin JL, Barraza J, Zak PJ, Mitkidis P (2019) Stories vs. facts: triggering emotion and action-taking on climate change. Climatic Change 154:19-36.

National Academies of Sciences, Engineering and Medicine (2017) Communicating science effectively: a research agenda. Washington, DC: National Academies.

National Institutes of Health (2008) Mental disorders cost society billions in unearned income. https://www.nih.gov/news-events/news-releases/ mental-disorders-cost-society-billions-unearned-income.

Neumann D, Spezio ML, Piven J, Adolphs R (2006) Looking you in the mouth: abnormal gaze in autism resulting from impaired top-down modulation of visual attention. Soc Cogn Affect Neurosci 1:194-202.

Nijhof AD, Willems RM (2015) Simulating fiction: individual differences in literature comprehension revealed with fMRI. PLoS One 10:e0116492.

Nimgaonkar VL, Prasad KM, Chowdari KV, Severance EG, Yolken RH (2017) The complement system: a gateway to gene-environment interactions in schizophrenia pathogenesis. Mol Psychiatry 22:1554-1561.

Oliver K, Cairney P (2019) The dos and don'ts of influencing policy: a systematic review of advice to academics. Palgrave Commun 5:21.

Otero-Millan J, Macknik SL, Robbins A, Martinez-Conde S (2011) Stronger misdirection in curved than in straight motion. Front Hum Neurosci 5:133.

Quirk GJ (2019) Neuroscience research and mentoring in Puerto Rico: what succeeds in this environment? J Neurosci 39:776-782.

Rieiro H, Martinez-Conde S, Macknik SL (2013) Perceptual elements in Penn and Teller's "Cups and Balls" magic trick. PeerJ 1:e19.

Selemon LD, Zecevic N (2015) Schizophrenia: a tale of two critical periods for prefrontal cortical development. Transl Psychiatry 5:e623.

Silberman S (2019) Greta Thunberg became a climate activist not in spite of her autism, but because of it. Vox. https://www.vox.com/first-person/ 2019/5/6/18531551/autism-greta-thunberg-speech.

Tamir DI, Bricker AB, Dodell-Feder D, Mitchell JP (2016) Reading fiction and reading minds: the role of simulation in the default network. Soc Cogn Affect Neurosci 11:215-224.

Töpper J, Glaser M, Schwan S (2014) Extending social cue based principles of multimedia learning beyond their immediate effects. Learn Instruction 29:10-20.

Webster N (1969) Webster's third new international dictionary of the English language, unabridged: a Merriam-Webster. Cambridge, MA: Riverside.

Wellcome Trust Case Control Consortium (2007) Genome-wide association study of 14,000 cases of seven common diseases and 3,000 shared controls. Nature 447:661-678.

Whitney C, Huber W, Klann J, Weis S, Krach S, Kircher T (2009) Neural correlates of narrative shifts during auditory story comprehension. Neuroimage 47:360-366.

Willems RM, Jacobs AM (2016) Caring about Dostoyevsky: the untapped potential of studying literature. Trends Cogn Sci 20:243-245.

Williams H, McOwan PW (2014) Magic in the machine: a computational magician's assistant. Front Psychol 5:1283.

Witt SH, Streit F, Jungkunz M, Frank J, Awasthi S, Reinbold CS, Treutlein J, Degenhardt F, Forstner AJ, Heilmann-Heimbach S, Dietl L, Schwarze CE, Schendel D, Strohmaier J, Abdellaoui A, Adolfsson R, Air TM, Akil H, Alda M, AllieyRodriguez N, et al. (2017) Genome-wide association study of borderline personality disorder reveals genetic overlap with bipolar disorder, major depression and schizophrenia. Transl Psychiatry 7:e1155.

Yuan Y, Major-Girardin J, Brown S (2018) Storytelling is intrinsically mentalistic: A functional magnetic resonance imaging study of narrative production across modalities. J Cogn Neurosci 30:1298-1314.

Zacks JM, Speer NK, Swallow KM, Maley CJ (2010) The brain's cuttingroom floor: segmentation of narrative cinema. Front Hum Neurosci 4:168. 